\title{
UM CONTO DE FADAS TRANSCENDENTAL
}

Denize da Encarnação Pontes

Prof $^{a}$ da Rede Pública Municipal de Praia Grande

\section{RESUMO}

O presente artigo tem como objetivo central, mostrar a trajetória e as diferentes versões do conto de fadas Chapeuzinho Vermelho, que de tantas maneiras de contar essa história encantou e ainda encanta diversas gerações que de seu texto se apropriaram, seja através da história lida ou da história contada, estimulando de alguma forma o gosto pela leitura. Neste estudo serão apresentadas as passagens desse conto de fadas pelos séculos, saindo das rodas de fogueira até chegar às telas do cinema. A metodologia adotada para a realização dessa pesquisa, foi através do estudo bibliográfico, com revisão de literatura, de assuntos pertinentes à essa temática. Sendo assim, espera-se com este artigo, mostrar que não importa qual vertente será utilizada na apresentação de um conto, mas o verdadeiro sentido está na forma de introduzir a magia, sem fugir da essência da história, contribuindo assim, para o desenvolvimento global do ser humano, bem como para a formação de leitores.

Palavras-Chave: Versões; trajetórias; Contos de Fadas; Imaginário Infantil; Medo.

\section{1- INTRODUÇÃO}

Os contos de fadas, à medida que foram se aproximando da infância, foram se transformando até chegar nas versões que hoje conhecemos. Perpassaram séculos e se mantiveram como instrumentos importantes de ensinamentos e de deleite para adultos e crianças. Se nos lançarmos no tempo, de volta à nossa infância, é provável não ser necessário recorrer a grande esforço, para recordarmos com prazer daquelas belas histórias que marcaram nossos primeiros anos de vida. Dentre elas, certamente encontraremos os contos de fadas. Tais histórias arrastam-se pelo tempo, disseminadas ao longo de diversas gerações e contém, ainda hoje, o poder de alegrar os dias e embalar os sonhos de tantas crianças em todo o mundo.

Diante do exposto, enfatiza-se a importância deste estudo para o conto de fadas Chapeuzinho Vermelho, que já faz parte da cultura popular, estando presente em diversos momentos da História. E o seu encantamento é tão fascinante que se torna gratificante a construção deste estudo, no sentido de realizar uma espécie de viagem no tempo para essa abordagem, saindo 
das rodas de fogueira e entrando nas telas do cinema. Desta forma, tomando conhecimento da trajetória desse conto, a atual pesquisa possui também como foco, apresentar o poder que as histórias podem exercer na formação de futuros leitores.

Por conta disso, ao entrar nesse túnel do tempo, vale citar que no século XVII, a sociedade era sobretudo formada por camponeses. Eles trabalhavam e se distraíam juntos. Os contos ditos em voz alta eram, antes de tudo destinados aos adultos, que na maior parte, não sabiam ler. Para eles, era o momento de exprimir não só a dura realidade em que viviam, mas também de sonhar e mudar de vida durante uma história. Naquela época, a palavra oral ainda primava sobre a escrita, sendo o livro de difícil aquisição.

As histórias eram contadas ao pé da lareira ou em tabernas, onde todos reuniam-se, inclusive as crianças. Os contos originais dos camponeses, na sua grande maioria, eram formados de elementos grotescos e obscenos, pouco se importando com a presença do público infantil.

Já os contos de fadas, por outro lado, surgiram bem antes disso, ou seja, antes que houvesse na sociedade uma intencionalidade em se fazer ou escrever algo dirigido às crianças. Conforme Radino:

Os contos de fadas são considerados por Darnton documentos históricos. Surgiram ao longo dos séculos e foram sofrendo transformações conforme a sociedade e a cultura a que se dirigiam. Segundo o autor os contos franceses retratam a França entre os séculos XV e XVIII, mostrando a realidade brutal em que viviam os camponeses (2003, p.65).

Vale destacar, que alguns contos, porém, vieram a público em pequenos livretos azuis a baixo preço. Vendidos pelos mercadores ambulantes, eles ficavam ao lado dos objetos da vida cotidiana. Ocorre que as crianças mais ricas passavam a infância com as amas, provenientes do povo. Estas últimas relatavam em francês esses contos de fadas que se transmitiam oralmente de geração em geração. "A passagem dos contos orais para a cultura escrita implica um processo de transformação, paradoxalmente profundo e perceptível à primeira vista". (PERRAULT, 2004, p. 31).

\section{2- O CONTO DE FADAS CHAPEUZINHO VERMELHO}

\section{2-1 A TRAJETÓRIA}

Em razão do âmbito abrangente, o atual trabalho contribuirá com informações específicas para o conto de fadas Chapeuzinho Vermelho, por ter este conto uma trajetória reveladora e enriquecedora, sendo esse o objetivo central desta pesquisa.

Segundo estudos já realizados, esse conto sofreu inúmeras adaptações, mudanças e releituras através dos tempos. Mesmo assim, da cultura popular mundial, ele é uma das fábulas mais conhecidas de todos os tempos. 
As origens desse conto podem ser rastreadas até por vários países europeus e mais do que provavelmente anteriores ao século XVII. Chapeuzinho Vermelho era narrada por camponeses na França, Itália e Alemanha, sempre com um caráter muito popular.

Versões antigas, contadas ao pé da lareira ou em tabernas, mostram uma jovem heroína esperta que não precisa se valer de caçadores para escapar do lobo e encontrar seu caminho de volta para casa.

Numa edição comentada e ilustrada dos contos de fadas, Maria Tatar em seu livro Contos de fadas, 2004, disponibiliza uma curiosa versão, de feitio mais antigo, dessa história.

O conto chama-se A História da Avó e tem as características das narrativas folclóricas, não originalmente direcionadas para as crianças. Por isso, não há nele nenhuma mensagem pedagógica subliminar, nem preocupação em suprimir os elementos grotescos.

A História da Avó merece um comentário, pois está fora do padrão habitual. O começo é igual, mas mais sucinto, sem o sermão materno, que está totalmente ausente. Torna-se curioso citar essa versão para entendermos como esse conto foi sendo modificado e suavizado através dos tempos.

E para melhor compreensão e conhecimento desse fato, vale citar uma breve sinopse, onde vemos que o diálogo com o Lobo é breve, apenas este pergunta por onde ela vai e segue o outro caminho correndo para chegar antes. Devora a avó, mas não toda, deixa um pouco de carne e uma garrafa de sangue para depois. Quando Chapeuzinho chega, ele pede-lhe para deixar a cesta na despensa e a convida para comer a carne e beber o vinho (ou melhor, $o$ sangue) que estão na prateleira.

No fundo da cena, um gato falante comenta que é preciso ser uma porca para comer da carne da avó e beber o seu sangue. A menina não parece dar importância a essa observação, mas está atenta ao convite do Lobo para irem para a cama: tire a roupa, minha filha, e venha para a cama comigo... a cada peça de roupa que ela tira, pergunta para o Lobo onde colocar, ele responde sempre o mesmo: jogue no fogo, minha filha, não vai precisar mais dela... O striptease é detalhado, quanto ao avental, ao vestido, ao corpete, a anágua e finalmente as meias, e mais minucioso será, quanto mais o narrador quiser acentuar as tintas eróticas da cena. Quando ela finalmente deita, depois do diálogo conhecido sobre as partes grandes e peludas do corpo do Lobo, a menina tem uma súbita vontade de urinar e pede para se aliviar lá fora, ao que o Lobo responde que faça na cama mesmo. A menina insiste, e ele a deixa sair, mas com um cordão amarrado no pé. A menina amarra o cordão numa árvore e dispara para casa tão rápido que o Lobo não alcança.

Portanto, desde essa narrativa da tradição oral, que considera-se a mais antiga, os aspectos eróticos (em que Chapeuzinho se despe para entrar na cama do Lobo-Vovozinha) e canibalísticos (quando, antes de comer a menina, o Lobo lhe serve a carne e o sangue da avó), foram sendo suprimidos, substituídos e modificados, confirmando assim suas alterações na trajetória desse conto. 


\section{2-2 A PASSAGEM DO SÉCULO}

Entrando para o final do século XVII e continuando no século XVIII, essa história foi sendo suavizada, onde Charles Perrault publica a primeira adaptação literária impressa de Chapeuzinho vermelho em 1697, mas mesmo assim, poucos pais se dispunham a ler aquela versão do conto para os filhos, pois sua primeira versão francesa em papel não contém um bom final para a menina: depois do diálogo clássico, ela é definitivamente devorada pelo Lobo.

Essa versão foi escrita para a corte do rei Louis XIV, destinada a um público que o rei entretinha com festas extravagantes e prostitutas, que pretendia levar uma moral as mulheres para perceberem os avanços de maus pretendentes e sedutores. Um coloquialismo comum da época era dizer que uma menina que perdeu a virgindade tinha visto "o lobo". O texto de Perrault tem um caráter de fábula moral, ensina que quem transgride as regras se expõe ao perigo, é punido e fim de história. Inclusive algumas versões de Perrault trazem uns versinhos finais que alertam as meninas ingênuas sobre o perigo dos lobos de fala mansa:

Vemos aqui que as meninas e, sobretudo, as mocinhas lindas, elegantes e finas, não devem a qualquer um escutar. E se fazem-no, não é surpresa, que do lobo virem o jantar. Falo "do” lobo, pois nem todos eles são de fato equiparáveis. Alguns são até muito amáveis, serenos, sem fel nem irritação. Esses doces lobos, com toda a educação, acompanham as jovens senhoritas pelos becos afora e além do portão. Mas ai! Esses lobos gentis e prestimosos são, entre todos, os mais perigosos (PERRAULT,Paris: Barbin,1697).

Os contos de Perrault são o resultado de uma censura bastante nítida de todos os elementos e motivos que, na versão original, poderiam chocar ou simplesmente não ser compreendidos pelo público mundano. Mas Perrault não se contentou em cortar o que os contos tinham de vulgar. Ele transformou a narrativa e a adaptou à sociedade da época. Originários, na maior parte, do folclore francês, os contos adaptados literalmente por Perrault não pertenciam de modo algum à literatura infantil, mas à literatura oral, sempre em movimento, destinada aos adultos dos povoados, e eram concebidos para o entretenimento noturno.

\section{2-2-1 UM NOVO SÉCULO}

Já no século XIX, a versão de Chapeuzinho Vermelho ganha um caráter de conto de fadas, onde cento e sessenta anos depois (1857), os irmãos Grimm escrevem uma continuação do conto. Duas versões da história foram contadas a Jacob Grimm e seu irmão Wilhelm Grimm, a primeira por Jeanette Hassenpflug (1791-1860) e a segunda por Marie Hassenpflug (17881856).

Os irmãos registram a primeira versão para o corpo principal da história e a segunda em uma sequência do mesmo. Nesta, após Chapeuzinho ter sido devorada, um lenhador que estava passando em frente à casa da avó da menina, escutou o ronco do lobo que dormia de barriga cheia. Ele entrou e cortou - lhe a barriga, retirando a avó e a neta vivas de seu ventre; após, os três preencheram o espaço vazio do estômago do animal com pedras. O lobo acordou com 
sede e acabou afundando na água que pretendia beber, morrendo em seguida. Perrault é quase certamente a fonte do primeiro conto. No entanto, os Grimm, modificaram o final.

Historicamente, os irmãos Grimm evidenciaram a qualidade e a imaginação das histórias alemãs. Ao mesmo tempo, enriqueceram o fundo comum das histórias de fadas, contribuindo com versões novas e envolventes de histórias de caráter universal. Há uma evidente preocupação educativa por parte dos irmãos Grimm, manifesta na forma como eles desenvolvem determinadas características de seus manuscritos. Outros temas, considerados imorais ou demasiado cruéis, desaparecem.

E com relação a Chapeuzinho vermelho, apesar de os finais das histórias de Perrault e dos irmãos Grimm diferirem, seus inícios são bastante similares. Temos uma menina adorável, conhecida de todos pelo capuz vermelho, presenteado pela avó, o qual andava sempre vestindo. Um dia, sua mãe pede - lhe que leve uns bolinhos e vinho (ou manteiga) para sua avó que vivia na floresta. Em Grimm, essa ordem é acompanhada de um pequeno sermão:

Trate de sair agora mesmo, antes que o sol fique quente demais, e, quando estiver na floresta, olhe para a frente como uma boa menina e não se desvie do caminho. Senão pode cair e quebrar a garrafa, e não sobrará nada para a avó. E quando entrar, não se esqueça de dizer bom-dia e não fique bisbilhotando pelos cantos da casa...

Na versão dos Grimm Chapeuzinho, disposta a obedecer, pega o caminho conforme lhe fora indicado, mas encontra-se com o Lobo. No primeiro diálogo dos dois, cheio de gentilezas, ele toma a iniciativa e lhe pergunta aonde ela vai. Prontamente a menina conta ao Lobo sua missão, seu trajeto e a localização precisa da casa da avó. $\mathrm{O}$ ardiloso animal elabora então um plano para devorar não uma, mas duas criaturas. Para isso precisa de tempo, então faz Chapeuzinho ver como o sol está lindo e quantas flores há para colher pelo caminho. A menina se entusiasma com a proposta, se distrai com as flores e admirando borboletas, e ele consegue chegar antes à casa da avó. O Lobo chega antes à casa da avó, anuncia-se como sendo a neta e aproveita para devorar a velha, vestindo suas roupas de dormir e deitando-se em sua cama, à espera da menina. Chapeuzinho chega depois, e, nesse momento ocorre o clássico diálogo, que é sempre o clímax da narrativa. Logo após, ambas são devoradas, em seguida surge o lenhador que acaba salvando-as e termina com a morte do Lobo.

$\mathrm{Na}$ análise desse conto, percebe-se que as várias versões frisam que ela não teve medo, pois não sabia do perigo que corria. E por mais variações que a história possa produzir, existem falas que são como um núcleo permanente. Porém, fica claro a intenção dos Grimm em utilizar o conto, como uma forma de alertar o público sobre os perigos que podem surgir quando não se leva a sério uma tarefa designada e as consequências que podem ocasionar.

\section{2-2-2- O SÉCULO XX}

Neste século, a interpretação de Chapeuzinho Vermelho foi muito popular, com novas versões sendo escritas e traduzidas, especialmente na esteira da análise freudiana, desconstrução e teoria crítica feminista. A partir da modernidade, começou a haver uma distinção entre produtos culturais para adultos e produtos culturais para crianças, esse tempo levou isso tudo ao extremo, e cada idade passou a ter seus produtos bem delimitados. 
A cultura assimilou as leis do mercado, incorporando suas prerrogativas de consumo e publicidade. Com o passar dos anos, em função das intenções pedagógicas e mercadológicas, se torna então importante a definição de um público-alvo. E Chapeuzinho Vermelho passa a ter um forte caráter infantil.

Graças a isso, o grau de especialização da cultura produzida para a infância tornou-se algo a ser estabelecido com precisão. Levando em conta a psicologia de cada época da vida, foram surgindo ofertas culturais diferenciadas, que estiveram sob a suspeita adulta de serem prejudiciais ou deformadores da mente infantil. Ao contrário dessa preocupação, os contos de fadas ficaram isentos desse tipo de desconfiança e continuaram a ter um grande apreço a esse tipo de narrativa. $O$ único senão é um certo filtro quanto a passagens mais cruas.

Alguns contos foram submetidos a uma certa censura, embora seu conteúdo tivesse sido mantido. Há muito para se pensar sobre os contos da tradição oral que se perpetuam na intimidade dos lares, passando a fazer parte da formação das crianças.

\section{2-2-3- NO ATUAL SÉCULO}

O século XXI, trouxe ainda novas versões do conto abordado. Uma releitura de Chapeuzinho Vermelho que traz as tendências da mídia virtual foi publicada na obra Bonezinho Vermelho e a internet no século XXI, por Ivone Gomes de Assis, em 2005.

Nesta obra ilustrada, a vovozinha é uma hacker, que se disfarça até nas preferências do cotidiano, afirmando não gostar de nada que é tecnologia. A figura "feia" da vovó tenta quebrar o mito que muitos carregam ao pensar que a voz e a escrita, suave e gostosa, dos participantes de chats, sempre pertencem a pessoas bonitas e cheias de boa intenção. É uma obra bilíngue para crianças e adultos. Chico Buarque também faz uma paródia do conto na publicação de Chapeuzinho Amarelo, para o público pré-adolescente e Guimarães Rosa, em Fita Verde no Cabelo, traz uma versão para adolescentes.

Porém, mesmo com inúmeras versões e contribuições no estudo desse conto, Chapeuzinho Vermelho continua tocando em muitas angústias da infância, mas especialmente naquela que os psicanalistas chamam "o medo de ser devorado". Embora a história de Perrault e o conto dos Grimm possam tomar um rumo violento demais para algumas crianças, para outras essas mesmas histórias terminarão com uma exclamação de prazer e um pedido de bis.

E para os que se irritam com a incapacidade de Chapeuzinho de perceber que a criatura deitada na cama de sua avó é um lobo, como em Perrault e nos Grimm, as histórias The Little Girl and the Wolf, de James Thurber, e LittleRedRiding Hood and the Wolf, de Roald Dahl, são bons remédios. Na versão de Thurber, assistimos à menina tirando uma pistola automática da sua cestinha e matando o lobo a tiros. E a Chapeuzinho de Dahl saca uma pistola de seu bermudão e, numa questão de semanas, desfila com um "lindo casaco de pele de lobo".

E como já era de se esperar, o conto Chapeuzinho Vermelho entra nas telas do cinema, também com inúmeras versões, onde é lançado em 1984 o filme de drama e fantasia The CompanyofWolves (A Companhia dos Lobos), de autoria da romancista britânica Angela Carter, que retrata a maturidade da mulher e sua vida sexual numa metáfora do conto de 
Chapeuzinho Vermelho. No filme, Rosaleen é uma jovem e ingênua aldeã que ouve de sua avó histórias sobre os terríveis lobos que vivem na floresta e se disfarçam de homens para seduzir e devorar garotinhas.

As adaptações cinematográficas também tomam direções diferentes como se pode ver em Freeway-Sem saída (1996), de Matthew Bright, mas exploram infalivelmente as dimensões eróticas da história. Em 2011, surge uma versão mais sombria do conto, apresentada no filme RedRiding Hood (A Garota da Capa Vermelha), onde um lobisomem assombra um pequeno vilarejo no qual vive a garota Valerie (interpretada por Amanda Seyfried, com direção de Catherine Harwicke), que deve escolher entre o casamento prometido pela sua mãe e a fuga planejada com seu amor de infância, ao mesmo tempo que desconfia de quem possa ser o lobo.

Já em 2014, Chapeuzinho é um dos contos de fadas que aparece no filme musical "Intothe Woods", da Disney, com o nome em português "Caminhos da floresta". Nessa versão, a menina é salva do Lobo Mau graças ao protagonista, que deve quebrar um feitiço. Em retribuição, ela oferece sua capa, vermelha como o sangue, sendo um dos itens solicitados pela bruxa má (Meryl Streep), para desmanchar a maldição.

E finalmente em 2015, surge o filme Chapeuzinho Vermelho no Castelo das Trevas, de Rene Perez com Iren Levy, Nicole Stark, Robert Amstler e Alanna Forte. Nessa versão, baseado no clássico dos Irmãos Grimm, Chapeuzinho Vermelho é perseguida pelo Lobo Mau e acaba se escondendo em um antigo castelo em meio à floresta, em sua tentativa de fugir dos perigos escondidos na mata fechada. No entanto, uma vez lá dentro, Chapeuzinho irá descobrir novos perigos, problemas ainda maiores que a colocam em risco, de maneira iminente e fatal. A menina enfrenta seus próprios medos para que possa se ver livre para sempre.

Assim, vemos que versões contadas da história de Chapeuzinho Vermelho variam muito, com a adição ou a diminuição de elementos de acordo com cada autor, e pelo fato de não possuir propriamente um sentido único, acaba se tornando uma estrutura que permite gerar sentidos, por isso toda a interpretação será sempre parcial.

Os contos são formados como imagens de um caleidoscópio, o que muda são as posições dos elementos. Certos arranjos particularmente felizes por equilíbrio, beleza e força, cristalizam e formam algumas dessas narrativas que hoje conhecemos como as nossas histórias clássicas...(DIANA LICHTENSTEIN CORSO,2006).

\section{3- METODOLOGIA}

Para a elaboração deste trabalho, foi utilizada a metodologia de pesquisa descritiva e bibliográfica, realizando de modo constante a análise da literatura, compreendendo os trabalhos em que o assunto era pertinente a área de estudo e pesquisa, apresentados em artigos acadêmicos; livros e sites da internet. 
Portanto, as principais referências foram pautadas nos estudos de grandes educadores que se preocuparam com as abordagens da importância dos contos de fadas na formação de leitores e do universo da literatura infantil.

Em razão do âmbito abrangente, o atual trabalho buscou contribuir com informações específicas do conto de fadas Chapeuzinho Vermelho, por ter esta história uma trajetória reveladora e enriquecedora, que muito encanta nossos pequenos leitores, despertando assim, o interesse pelas histórias e pelos livros.

Espera-se, que esta pesquisa possa servir de apoio para que educadores e professores possam utilizar novas práticas pedagógicas que consiga desenvolver em seus alunos, o gosto e o prazer em ouvir e conhecer as histórias.

\section{CONSIDERAÇÕES FINAIS}

Após esse estudo realizado de forma objetiva e direta, percebe-se que Chapeuzinho Vermelho se tornou um conto capaz de conectar as pessoas ao elemento maravilhoso e à multiplicidade de sentidos que caracterizam o mito em todas as culturas e em todas as épocas, fazendo parte de um acervo cultural de histórias, através do qual a humanidade reconhece a si mesma.

Mesmo hoje, neste nosso mundo regido pela tecnologia de computadores e videogames, os contos de fadas tradicionais continuam a magnetizar as plateias atentas, e isso pode ser comprovado por qualquer contador de histórias. As histórias de fadas, conforme citado por Bruno Bettelheim, no livro A psicanálise dos contos de fadas, tem a capacidade de falar simultaneamente a todos os níveis da personalidade humana. Portanto eles falam tanto para crianças como para jovens ou adultos e, por trabalharem com uma linguagem marcadamente simbólica, estabelecem esse contato sem a intermediação do pensamento lógico.

Sendo assim, é possível afirmar que os contos de fadas possuem um lugar especial na vida das crianças, jovens e até mesmo os adultos, pois a oralidade, a leitura e a escrita se tornam atividades integradas e complementares utilizadas nas escolas e na vida, onde o primeiro contato da criança com o texto se dá através da narração oral, independentemente de estar ou não vinculadas ao livro.

Assim, defende-se que além da presença marcante dos contos de fadas nas gerações, eles devem também significar o resgate das culturas orais.

É notório de uma maneira geral, que dentre os contos tradicionais, Chapeuzinho Vermelho continua sendo um dos melhores contos de fadas que contribui para essa prática, onde vê-se que esse ele sobreviveu transpassando por vários séculos, sem perder a capacidade de estimular a imaginação das crianças, auxiliando nos conflitos psíquicos inconscientes que ainda dizem respeito às crianças de hoje.

A leitura desta pesquisa nos faz ver que o atual império das imagens não retirou a força das narrativas orais. 
E mesmo nos deparando com as mais novas versões cinematográficas, sempre estará viva a originalidade e a essência desse conto de fadas na mente de cada leitor ou ouvinte.

E hoje, tanto para os educadores, professores e contadores de histórias, o importante é saber que do ponto de vista do ouvinte infantil, não faz muita diferença se a história é passada ou contemporânea, a sua imaginação é livre para pensar e sentir os contos do jeito que elas quiserem.

\section{BIBLIOGRAFIA}

BeTtelheiM, Bruno. A psicanálise dos Contos de Fadas. $18^{a}$ ed., Rio de Janeiro: Paz e Terra, 1980 .

BUARQUE, Chico. Chapeuzinho Amarelo. 2ª ed., Rio de Janeiro: José Olímpio,1997.

CORSO, Diana Lichtenstein; CORSO, Mario. Fadas no Divã: Psicanálise nas Histórias Infantis. Porto Alegre: Artmed, 2006.

FROMM, Erich. A Linguagem Esquecida. Rio de Janeiro: Zahar, 1964.

MELLON, Nancy. A arte de contar histórias. Tradução Amanda Orlando Rodrigues. Rio de Janeiro: Rocco, 2006.

PERRAULT, Charles. Histórias ou Contos de Outrora. São Paulo: Landy Editora, 2004.

PERRAUlT, Charles. Le Petit Chaperon Rouge. Histoires ou Contes dutemps passe, avecdesmoralités. Paris: Barbin, 1697.

RADINO, Glória. Contos de fadas e realidade psíquica: a importância da fantasia no desenvolvimento. São Paulo: Casa do psicólogo, 2003.

SORIANO, Marc; JAHN, Heloisa. Contos de Grimm. São Paulo: Companhia das Letrinhas, 1996.

SOUZA, Renata Junqueira; FEBA, Berta Lúcia Tagliari. Leitura literária na escola: reflexões e propostas na perspectiva do letramento. $1^{a}$ ed.; Campinas, São Paulo: Mercado de letras, 2011.

SIMONSEN, Michéle. O Conto Popular. São Paulo: Martins Fontes, 1987.

TATAR, Maria. Contos de Fadas: Edição comentada e ilustrada. Rio de Janeiro: Zahar, 2004. 